\title{
Reproductive Health Needs of Women Living with HIV/AIDS in Yaounde, Cameroon
}

\author{
Robinson E. Mbu1,2*, William A. Takang3, Hortence J. Fouedjio1,2, Ekane Joan1,2, \\ Flobert Y. Fouelifack ${ }^{2}$, Florence N. Tumasang2, Rebecca N. Tonye' ${ }^{2}$, Robert J. I. Leke ${ }^{1}$ \\ ${ }^{1}$ Department of Obstetrics and Gynecology, Faculty of Medicine and Biomedical Sciences, University of \\ Yaounde 1, Yaounde, Cameroon \\ ${ }^{2}$ Maternity Unit, Central Hospital, Yaounde, Cameroon \\ ${ }^{3}$ Department of Obstetrics and Gynecology, Faculty of Health Sciences, University of Bamenda, Bamenda, \\ Cameroon \\ Email: ${ }^{*}$ rembu2000@yahoo.com
}

Received 20 December 2013; revised 20 January 2014; accepted 27 January 2014

Copyright (C) 2014 by authors and Scientific Research Publishing Inc.

This work is licensed under the Creative Commons Attribution International License (CC BY). http://creativecommons.org/licenses/by/4.0/

(c) (i) Open Access

\section{Abstract}

The population plagued with the HIV/AIDS pandemic in Cameroon is young, a generation that may desire or control fertility. For those who may become pregnant, the desire to have children may not be there. We carried out this study to look at the picture of the reproductive health needs of women living with HIV/AIDS in our setting. In this cross-sectional non-analytic design that lasted for three years, we employed both qualitative and quantitative methods to collect data from them after receiving ethical clearance (N221/CM/2009) from the National Ethics Committee. Consenting HIV infected women who were attending the "HIV Day Care" clinics and those who delivered and were in the post partum wards in four of our major hospitals in Yaounde were enrolled. Interviews were individualized. We used both CSPro version 4.1 and Statistical Package for Social Sciences (SPSS) version 19.0 softwares for data analysis. Four hundred and fifteen (415) women were enrolled; the mean age was $29 \pm 7.8$ years; the most represented age group was 24 - 29 years. They were single (36.14\%), well educated ( 5 out of 10 had attained university level of education), $61.20 \%$ revealed that their partners knew their HIV status, $82.4 \%$ believed that screening for cancer of the cervix was necessary for their status and $47.70 \%$ would want to be screened for some or all STIs. About $36.86 \%$ had the desire to have children, $57.1 \%$ of those who delivered did not plan to have the pregnancies out of which $82 \%$ would have wanted a modern method of contraception but did not have $(82 \%$ unmet needs). Modern contraceptive use was associated with age and individual characteristics such as level of education. It was $64.34 \%$ among women who had secondary level of education and below as against $35.66 \%$ among those who had high school level of education and above. Contraceptive use was also high among women who were unmarried as against those who were married $(89.64 \%$ vs $10.36 \%)$. The desire to have children decreased as

${ }^{*}$ Corresponding author. 
age increased (43.85\% vs $18.79 \%$ ) and was lower among married women compared to those who were single $(13.01 \%$ versus $49.64 \%)$. These women were found to have high unmet needs for modern contraception and showed interest in STIs and cervical cancer screening.

\author{
Keywords \\ Reproductive Health Needs; Family Planning; Unmet Needs; Cancer of the Cervix; Sexually \\ Transmitted Infections
}

\title{
1. Introduction
}

Since HIV/AIDS was reported in 1981 (CDC, 1981) and the virus isolated in 1983 [1], a lot of research has been carried out and efforts put towards its management and control. Financially, global spending on HIV/AIDS has increased 20 folds [2].

The apparent stabilization in prevalence rates in Cameroon (5.5\% in 2004 and 4.3\% in 2011 [3] [4]) could be argued out as a rise in AIDS related deaths and a decline in new infection. In 2009, UNAIDS estimated that there were over 33 million people infected with HIV worldwide and 70\% were found in Sub-Saharan Africa. Also, 2.6 million individuals were newly infected with HIV within the same year [5]. Cameroon with an HIV prevalence of $4.3 \%$ is considered one of the countries bearing the greatest burden in Central Africa.

To better manage the HIV/AIDS pandemic, a lot of input and efforts have been made to master and have a better understanding of its origin, structure, epidemiology, pathogenesis, diagnosis and management. Despite all these, a lot will be required in terms of resources to handle this pandemic (both human and material resources). We do not need to undermine programmatic challenges such as reinforcing prevention strategies that include prevention of mother to child transmission (PMTCT), provider initiated counseling and testing PICT) etc. We need to ensure that HIV infected individuals get the treatment and care they need and we need to develop strategies to improve the level of education and economic conditions of young women. Other challenges include the development, protection and promotion of the rights and duties of people living with HIV/AIDS and those of their spouses and children.

Young people are at the most risk. It is evident that they have reproductive health needs including family planning and fertility desires. Both the incidence and prevalence of women affected by HIV/AIDS are disproportionately high compared to men, representing more than half of the 33.3 million adults living with HIV/AIDS worldwide [5]. Also, about $80 \%$ of HIV infected women are in their reproductive ages [5] [6]. A range of successful and promising interventions to improve the sexual and reproductive health and rights of women living with HIV have been pronounced. These include the provision of contraceptives and family planning counseling as part of a common HIV package; ensuring early postpartum care, providing youth-friendly services, supporting information and skills building, supporting disclosure, providing cervical cancer screening, promoting condom use for dual protection against pregnancy and STIs/HIV and antiretrovirals [7].

Highly Active Antiretroviral Therapy (HAART) has improved the lives of women living with HIV/AIDS in Cameroon. Evidence shows that most of them need family planning, cervical cancer screening and screening for STIs [8] but these needs have not been evaluated here. In studies recently published, about $60 \%$ of pregnancies which occur among women living with HIV/AIDS in South Africa were unwanted, 50\% in Uganda and 75\% in Kenya [9]. As most of these women are young and are on HAART in Cameroon, their desires to have sex must not be under looked and the efferent pregnancies may be unwanted. This may boost the unsafe abortion industry. According to the World Health Organization (WHO), each individual has the right to reproduce, to regulate fertility and to express sexuality without danger [9].

Most surveys carried out in many Sub-Saharan African countries show that a relatively good proportion of women living with HIV/AIDS know at least one modern method of contraception but the most widely used methods vary with countries. In Cameroon, the most widely used methods are the male condom and oral pills. In Kenya, it is the pill that is most commonly used [10].

\section{Patients and Methods}

It was a cross-sectional non-analytic study. We began from January $20^{\text {th }} 2010$ and ended January $19^{\text {th }} 2013$, a 
period of three years. Four main hospitals which are affiliated to the Faculty of Medicine and Biomedical Sciences of the University of Yaounde 1 formed our study sites. They were the university teaching hospital, the general hospital, the gynecologic and pediatric hospital and the central hospital. They all have patient affluence and have HIV day care units (accredited treatment centers) and maternities. We obtained ethical clearance from the National Ethics Committee and authorizations from the directors of these hospitals. We combined both qualitative and quantitative approaches that were concurrent. We chose Mondays, Wednesdays and Fridays for the qualitative approach and Tuesdays, Thursdays and Saturdays for the quantitative approach. HIV positive women who were attending the "HIV Day Care" clinics and those who delivered and were in the post partum wards in the four hospitals and who accepted freely to participate in the study were enrolled consecutively. In the qualitative approach, we began with consent formalities followed by description of the study objectives and procedures individually in a private room in the Day Care clinics. The next step was a detailed interrogation using a preconceived questionnaire. The same procedure was carried out for HIV infected women who were found in the post partum wards during the same period in the quantitative approach. We exported data from CSPro version 4.1 to the Statistical Package for Social Sciences (SPSS) version 19.0 software for analysis. We expressed results in means as a measure of central tendency for data with normal distribution while we used median where the distribution was skewed. Results are presented in tables and cross tabulations and comparism for statistical differences where appropriate is made.

\section{Results}

A greater proportion of the women (26.02\%) were between 2529 years, single (36.14\%) educated (95.45\%), unemployed (51.10\%) and lived in urban areas (82.37\%) (Table 1). Quite a good number of them had been living with HIV for more than one year (52.30\%), with $61.11 \%$ of their partners knowing their HIV status. Only $7.73 \%$ of them had CD4 counts less than 350 and $82.37 \%$ were on HAART (Table 2). They showed interest in screening for STIs, screening for cancer of the cervix. They also showed interest in contraceptive use, desire to have children and in health education (Table 3). There was a significant relationship between age and contraceptive use $(p=0.045)$, level of education and contraceptive use $(p=0.015)$, marital status, religion and contraceptive use $(\mathrm{p}=0.001)$, Table 4 . The desire to have children was also significantly related to age $(\mathrm{p}=0.001)$

Table 1. Socio-demographic variables of women living with HIV/AIDS in Yaounde.

\begin{tabular}{ccc}
\hline Variable & Number of cases (N = 415) & (\%) \\
\hline Age range (yrs) & 108 & 26.02 \\
$25-29$ & & 23.85 \\
Marital status & 99 & 36.14 \\
Married & 150 & 95.42 \\
Single & & 4.58 \\
Level of education & 396 & 82.41 \\
Educated & 19 & 14.94 \\
Not educated & & \\
Religion & 342 & 48.92 \\
Christians & 62 & 51.08 \\
Muslims & & 17.59 \\
Employment status & 203 & \\
Paid salary & 212 & \\
Unpaid salary & & \\
Residence & 342 & \\
Urban & 73 & \\
Rural & & \\
\hline
\end{tabular}


Table 2. Past history and immunological status.

\begin{tabular}{|c|c|c|}
\hline Past history/immunological status & Number of cases $(N=415)$ & (\%) \\
\hline \multicolumn{3}{|l|}{ Duration Seropositivity } \\
\hline Less than six months & 59 & 14.21 \\
\hline More than six months & 139 & 33.49 \\
\hline More than one year & 217 & 52.29 \\
\hline \multicolumn{3}{|l|}{ Partner knows your HIV status } \\
\hline Yes & 254 & 61.20 \\
\hline No & 161 & 38.79 \\
\hline \multicolumn{3}{|l|}{ Is your partner HIV-positive } \\
\hline Yes & 164 & 39.52 \\
\hline No & 251 & 60.39 \\
\hline \multicolumn{3}{|l|}{ Most recent CD4 count } \\
\hline Over 500 & 153 & 36.86 \\
\hline Between 350 - 500 & 230 & 55.42 \\
\hline Below 350 & 32 & 7.71 \\
\hline \multicolumn{3}{|l|}{ On HAART } \\
\hline Yes & 342 & 82.40 \\
\hline No & 73 & 17.60 \\
\hline Need & Number of cases $(N=415)$ & $(\%)$ \\
\hline \multicolumn{3}{|l|}{ STIs screening } \\
\hline All STIs & 59 & 14.21 \\
\hline Just some STIs & 139 & 33.49 \\
\hline Screening of partner & 217 & 52.29 \\
\hline \multicolumn{3}{|l|}{ Need for Cancer screening } \\
\hline Cervical cancer & 342 & 82.40 \\
\hline Breast cancer & 161 & 38.79 \\
\hline \multicolumn{3}{|l|}{ Modern contraception (non-pregnant cases) } \\
\hline Using & 164 & 39.51 \\
\hline Would have used (unmet needs) & 251 & 60.48 \\
\hline \multicolumn{3}{|l|}{ Desire to have children } \\
\hline Yes & 153 & 36.86 \\
\hline No & 230 & 55.42 \\
\hline Not an issue & 32 & 7.71 \\
\hline \multicolumn{3}{|l|}{ Those who delivered } \\
\hline Did not want the pregnancy & 237 & 57.10 \\
\hline Would have wanted contraception & 340 & 82.92 \\
\hline
\end{tabular}

and level of education ( $\mathrm{p}=0.004)$, Table 5 .

\section{Discussion}

Reproductive health needs of women living with HIV/AIDS have been assessed and studies on this issue have 
Table 4. Relationship between contraceptive use and socio-demographic characteristics.

\begin{tabular}{ccc}
\hline Characteristics & Number of cases (N = 415) & (\%) \\
\hline Age (years) & 300 & 72.29 \\
$15-29$ & 115 & 27.71 \\
$30-49$ & & 64.34 \\
Level of education & 267 & 35.66 \\
Secondary and below & 148 & 10.12 \\
High school and above & & 89.88 \\
Employment status & 42 & 10.36 \\
Unemployed & 373 & 89.64 \\
Employed & & \\
Marital status & 43 & 61.45 \\
Married & 372 & $30 . .55$ \\
Unmarried & & \\
Religion & 255 & 160 \\
Christians & & \\
Muslims & & \\
\hline
\end{tabular}

Table 5. Relationship between fertility desire and socio-demographic characteristics.

\begin{tabular}{|c|c|c|}
\hline Characteristics & Number of cases $(\mathrm{N}=415)$ & $(\%)$ \\
\hline \multicolumn{3}{|l|}{ Age (years) } \\
\hline $15-29$ & 182 & 43.85 \\
\hline $30-49$ & 78 & 18.79 \\
\hline \multicolumn{3}{|l|}{ Level of education } \\
\hline Secondary and below & 118 & 28.43 \\
\hline High school and above & 142 & 34.22 \\
\hline \multicolumn{3}{|l|}{ Employment status } \\
\hline Unemployed & 52 & 12.53 \\
\hline Employed & 208 & 50.12 \\
\hline \multicolumn{3}{|l|}{ Marital status } \\
\hline Married & 54 & 13.01 \\
\hline Unmarried & 206 & 49.64 \\
\hline \multicolumn{3}{|l|}{ Religion } \\
\hline Christian & 215 & 51.81 \\
\hline Muslim & 38 & 9.16 \\
\hline
\end{tabular}

been carried out in many countries especially in Sub Saharan Africa. Reproductive health needs are varied and various, but the aim of this study was to evaluate these needs among women living with HIV/AIDS in our environment. Evidence has shown that most of them need family planning. The age group most represented was 25 29 years (26.02\%), followed by 30 - 34 years (19.1\%). These results are similar to what has been reported in several related studies [10]-[13]. This could be explained by the fact that sexual activity is high among respondents of these age groups [13]. Also, these age groups have the highest prevalence of HIV among women in Cameroon [14]. 
The women studied were largely single (36.14\%); married women represented $23.85 \%$ of the population, a finding consistent with reports in literature [15]. They were educated as only $4 \%$ of them had not received any formal education, just as has been reported in earlier studies in Cameroon [16]. Over half of the women had been diagnosed with HIV for more than a year (52.29\%), same as reported in some studies in Cameroon, Nigeria and Uganda [16]-[19]. With respect to CD4 count, 92.28\% of the women enrolled had values greater than 350 and $82.40 \%$ were on HAART. A good number of them (47.70\%) showed interest in screening for STIs, $82.40 \%$ in screening for cervical cancer and 38.79\% in screening for breast cancer (Table 3). These services do not form the common package of continuum of care in the management of women living with HIV/AIDS in our country even though the United States Centers for Disease Control and Prevention (CDC) has included them as part of AIDS-related illnesses [20]. A similar picture is observed in most of our countries as these services are not integrated or are just rudimentary [21] [22].

Demographic dividends of family planning are well known but unmet needs were evaluated to be very high in the general population of women living with HIV/AIDS in Cameroon including those who delivered (60.48\% and $82.92 \%$ respectively). Up to $57.10 \%$ of women who delivered confessed they did not want these pregnancies. Similar findings have been reported in Sub-Saharan Africa [23]-[27]. Contraceptive use was related to the level, of education, religion, employment and marital stati. Women who used modern methods of contraception were educated at or below secondary school level (64.34\%), employed (89.88\%), unmarried (89.64\%), Christians (61.45\%) (Table 4). Among the non-pregnant women interviewed, 36.86\% of them had the desire to have children. The main reason for wanting to have children was lineage continuity. The desire to have children was inversely proportional to age and level of education. As age and level of education increased, the desire to have children decreased. Conversely, the desire to have children showed a direct relationship with unmarried and employed stati (Table 5).

\section{Conclusion}

Reproductive health needs vary among women living with HIV/AIDS in Cameroon. Unmet needs are high for family planning or cancer and STIs screening. Modern contraceptive use was linked to age, marital status and level of education.

\section{References}

[1] Barre-Sinousi, F. and Cheman, J.C. (1998) Isolation of T-Lymphotropic Retrovirus from a Patient at Risk of AIDS. Science, 220, 868-871. http://dx.doi.org/10.1126/science.6189183

[2] UNAIDS (2010) Reports of the Global AIDS Epidemic.

[3] Institute National de la Statistique (2004) Enquête Démographique et de Santé Cameroun.

[4] Institute National de la Statistique (2011) Enquête Démographique et de Santé Cameroun.

[5] UNIAIDS and WHO (2009) The Joint United Nations Programme on HIV/AIDS and World Health Organization: AIDS Epidemic Update Geneva.

[6] Wu, H., Wu, P.Y., Li, S.Y., Chang, S.Y., Liu, W.C., Wu, C.H. et al. (2012) Maximizing the Potential of Voluntary Counseling and Testing for HIV and Sexually Transmitted Infections in a Population. Sexually Transmitted Infections, 88, 612-616. http://dx.doi.org/10.1136/sextrans-2011-050354

[7] Gay, J., Hardee, K., Croce-Galis, M. and Hall, C. (2011) What Works to Meet the Sexual and Reproductive Health Needs of Women Living with HIV/AIDS? Journal of the International AIDS Society, 14, 56. http://dx.doi.org/10.1186/1758-2652-14-56

[8] UNIAIDS/WHO (2005) The Joint United Nations Programme on AIDS and World Health Organization. Global HIV/AIDS and STI Surveillance. Report on the Global HIV/AIDS Epidemic. Geneva.

[9] Ciaranello, A.L., Freedberg, K.A., Weinstein, M.C., Lockman, S. and Walensky, R.P. (2008) Antiretroviral Drugs for Preventing Mother-to-Child Transmission of HIV in Sub Saharan Africa: Balancing Efficacy and Infant Toxicity. AIDS, 22, 2359-2369. http://dx.doi.org/10.1097/QAD.0b013e3283189bd7

[10] Ngum, N.K. (2008) Survey of Knowledge Attitude and Practice of the Oral Contraceptive Pill among High School Students in Kumba, South West Region of Cameroon. M.D. Thesis (unpublished), FMBS, University of Yaounde 1, Yaounde.

[11] Kakaire, O., Osinde, M.O. and Kaye, D.K. (2010) Factors That Predict Fertility Desires for People Living with HIV/AIDS Infection at a Support Center in Kabale, Uganda. Reproductive Health, 7, 27. 
http://dx.doi.org/10.1186/1742-4755-7-27

[12] Petruney, T., Harlan, S.V., Lanham, M. and Robinson, E.T. (2010) Increasing Support for Contraception as HIV Prevention: Stakeholder Mapping to Identify Influential Individuals and Their Perceptions. PLoS One, 5, 10781. http://dx.doi.org/10.1371/journal.pone.0010781

[13] Fon, E.A. (2011) Pregnancy Related Decisions among HIV Infected Women: The Case of Bamenda in the North West Region of Cameroon. M.D. Thesis (unpublished), FMBS, University of Yaounde 1, Yaounde.

[14] Kongnyuy, E.J., Soskolne, V. and Alder, B. (2008) Hormonal Contraception, Sexual Behavior and HIV Prevalence among Women in Cameroon. BMC Women's Health, 8, 19. http://dx.doi.org/10.1186/1472-6874-8-19

[15] Cooper, D., Harries, J., Myer, L., Omer, P. and Bracken, H. (2007) “Life Is Still Going on”: Reproductive Intentions among HIV Positive Women and Men in South Africa. Social Science \& Medicine, 65, 274-283. http://dx.doi.org/10.1016/j.socscimed.2007.03.019

[16] Erhabor, O., Akani, C.I. and Eyindah, C.E. (2012) Reproductive Health Options among HIV-Infected Persons in the Low-Income Niger Delta of Nigeria. HIV/AIDS, 4, 29-35.

[17] Nattabi, B., Li, J., Thompson, S.C., Orach, C.J. and Earnest, J. (2009) A Systematic Review of Factors Influencing Fertility Desire and Intentions among People Living with HIV/AIDS: Implications for Policy and Service Delivery. AIDS and Behavior, 13, 949-968. http://dx.doi.org/10.1007/s10461-009-9537-y

[18] Yeatman, S.E. (2009) The Impact of HIV Status and Perceived Status on Fertility Desires in Rural Malawi. AIDS and Behavior, 13, 12-19. http://dx.doi.org/10.1007/s10461-009-9534-1

[19] Kipp, W., Heys, J., Jhangri, G.S., Alibhai, A. and Rubaale, T. (2011) Impact of Antiretroviral Therapy on Fertility Desire among HIV-Infected Persons in Rural Uganda. Reproductive Health, 8, 27. http://dx.doi.org/10.1186/1742-4755-8-27

[20] Update to CDC's US Medical Eligibility Criteria for Contraceptive Use 2010: Revised Recommendations for the Use of Hormonal Contraceptives among Women at High Risk of HIV Infection or Infected with HIV. MMWR, 61, 449-452.

[21] Holmes, R.S., Hawes, S.E., Toure, P., Dem, A., Feng, Q., Weiss, N.S., et al. (2009) HIV Infection as Risk Factor for Cervical Cancer and Cervical Intraepithelial Neoplasm in Senegal. Cancer Epidemiology, Biomarkers \& Prevention, 18, 2442-2446. http://dx.doi.org/10.1158/1055-9965.EPI-08-0956

[22] Mutyaba, T., Mirembe, F., Sandin, S. and Weiderpass, E. (2010) Evaluation of "See and Treat" Strategy and Role of HIV on Cervical Cancer Prevention in Uganda. Reproductive Health, 7, 4. http://dx.doi.org/10.1186/1742-4755-7-4

[23] Benzaken, A., Sabido, M., Galban, E., Rodrigues-Dultra, D.L., Leturiondo, A.L. and Mayaud, P. (2012) HIV and Sexually Transmitted Infections at the Borderlands: Situational Analysis of Sexual Health in the Brazilian Amazon. Sexually Transmitted Infections, 88, 294-300. http://dx.doi.org/10.1136/sextrans-2011-050309

[24] White, R., Celum, C., Wasserheit, J., Aral, S. and Hayes, R. (2008) Control of Sexually Transmitted Infections for HIV Prevention. Lancet, 372, 1297. http://dx.doi.org/10.1016/S0140-6736(08)61541-X

[25] Reynolds, H.W., Janowitz, B., Wilcher, R. and Cates, W. (2008) Contraception to Prevent HIV-Positive Births: Current Contribution and Potential Cost Savings in PEPFAR Countries. Sexually Transmitted Infections, 84, 49-53. http://dx.doi.org/10.1136/sti.2008.030049

[26] Mossi, H.M. (2008) Comportement Contraceptive des Clients et Facteurs de Choix de Méthodes Contraceptives à Yaoundé. M.D. Thesis (unpublished), FMBS, University of Yaounde 1, Yaounde.

[27] Robinson, J.A., Jamshidi, R. and Burkr, A.E. (2012) Contraception for HIV-Positive Women: A Review of Interactions between Hormonal Contraception and Antiretroviral Therapy. Infectious Diseases in Obstetrics and Gynecology, 2012, 890160. http://dx.doi.org/10.1155/2012/890160 